\title{
Hirschsprung disease, microcephaly, mental retardation, and characteristic facial features: delineation of a new syndrome and identification of a locus at chromosome 2q22-q23
}

\author{
D R Mowat, G D H Croaker, D T Cass, B A Kerr, J Chaitow, L C Adès, N L Chia, \\ M J Wilson
}

Department of Clinical Genetics, Royal Alexandra Hospital for Children, Westmead, Sydney, NSW 2124,

Australia

D R Mowat

L C Adès

M J Wilson

\section{Department of}

Surgery, Royal

Alexandra Hospital for

Children, Westmead,

Sydney, NSW 2124,

Australia

G D H Croaker

D T Cass

Department of

Medical Genetics, St

Mary's Hospital,

Manchester M13 0JH,

UK

B A Kerr

\section{Department of}

Medicine, Royal

Alexandra Hospital for

Children, Westmead,

Sydney, NSW 2124,

Australia

J Chaitow

Department of

Cytogenetics, Royal

Alexandra Hospital for

Children, Westmead,

Sydney, NSW 2124,

Australia

N L Chia

Correspondence to:

Dr Wilson.

Received 8 January 1997

Revised version accepted for publication 29 January 1998

\begin{abstract}
We have identified six children with a distinctive facial phenotype in association with mental retardation (MR), microcephaly, and short stature, four of whom presented with Hirschsprung (HSCR) disease in the neonatal period. HSCR was diagnosed in a further child at the age of 3 years after investigation for severe chronic constipation and another child, identified as sharing the same facial phenotype, had chronic constipation, but did not have HSCR. One of our patients has an interstitial deletion of chromosome 2, del(2)(q21q23). These children strongly resemble the patient reported by Lurie et $a l$ with HSCR and dysmorphic features associated with del(2)(q22q23). All patients have been isolated cases, suggesting a contiguous gene syndrome or a dominant single gene disorder involving a locus for HSCR located at 2q22-q23.

Review of published reports suggests that there is significant phenotypic and genetic heterogeneity within the group of patients with HSCR, MR, and microcephaly. In particular, our patients appear to have a separate disorder from Goldberg-Shprintzen syndrome, for which autosomal recessive inheritance has been proposed because of sib recurrence and consanguinity in some families. (F Med Genet 1998;35:617-623)
\end{abstract}

Keywords: Hirschsprung disease; mental retardation; microcephaly; chromosome 2

The association of Hirschsprung disease (HSCR), microcephaly, and mental retardation was first described in a pair of sibs by Goldberg and Shprintzen in 1981.' This association has been reported with other features including cleft palate, ${ }^{1-3}$ iris coloboma, ${ }^{4}$ congenital heart disease, ${ }^{256}$ and abnormal cranial imaging. ${ }^{14-7}$ Autosomal recessive inheritance has been proposed in view of parental consanguinity ${ }^{4}$ and sib recurrence in three families. ${ }^{127}$
We report six children with a distinctive facial phenotype in association with HSCR, $M R$, and microcephaly, one of whom has an interstitial deletion of chromosome 2q. The first five patients are from New South Wales, Australia and the sixth from Manchester, UK. We reviewed the previous case reports of HSCR, MR, and microcephaly, and of patients with chromosome $2 \mathrm{q}$ deletions, ${ }^{8-15}$ and compared the findings to those of our patients. Polymorphic microsatellite markers encompassing the region of cytogenetic deletion were typed in the first five families.

\section{Case reports}

PATIENT 1 (FIG 1)

This boy is the fifth of six children of non-consanguineous parents. His birth weight was $3700 \mathrm{~g}$, length $50 \mathrm{~cm}$, and head circumference $33 \mathrm{~cm}$. He did not pass meconium, developed bilious vomiting and abdominal distension on day 5, and HSCR was diagnosed by rectal suction biopsy. Aganglionosis was found to extend to the splenic flexure and he had an initial defunctioning colostomy, followed by a Duhamel pull through procedure at the age of 8 months. He had bilateral grade IV vesicoureteric reflux and underwent bilateral reimplantation of his ureters at 9 months of age.

At 4 months he had hypotonia and poor head growth; cerebral ultrasound suggested partial agenesis of the corpus callosum, but a cranial CT scan was normal. At 2 years of age he developed recurrent seizures, which continued intermittently for another year, but by the age of 5 were well controlled with sodium valproate and clonazepam. He required a Nissen fundoplication for severe gastro-oesophageal reflux and failure to thrive. At $5 \frac{1 / 2}{2}$ years he vocalised but had no recognisable words, was able to sit independently, crawl, pull to stand, and walked in a walker. His hearing and vision were normal and he had a generally placid personality.

On examination at the age of $41 / 2$ years his height was $96 \mathrm{~cm}$ (<3rd centile), weight $14.5 \mathrm{~kg}$ (10th centile), and head circumference $47.5 \mathrm{~cm}$ ( 3 rd centile). He had striking blue eyes, sparse, widely separated eyebrows, mildly downward 

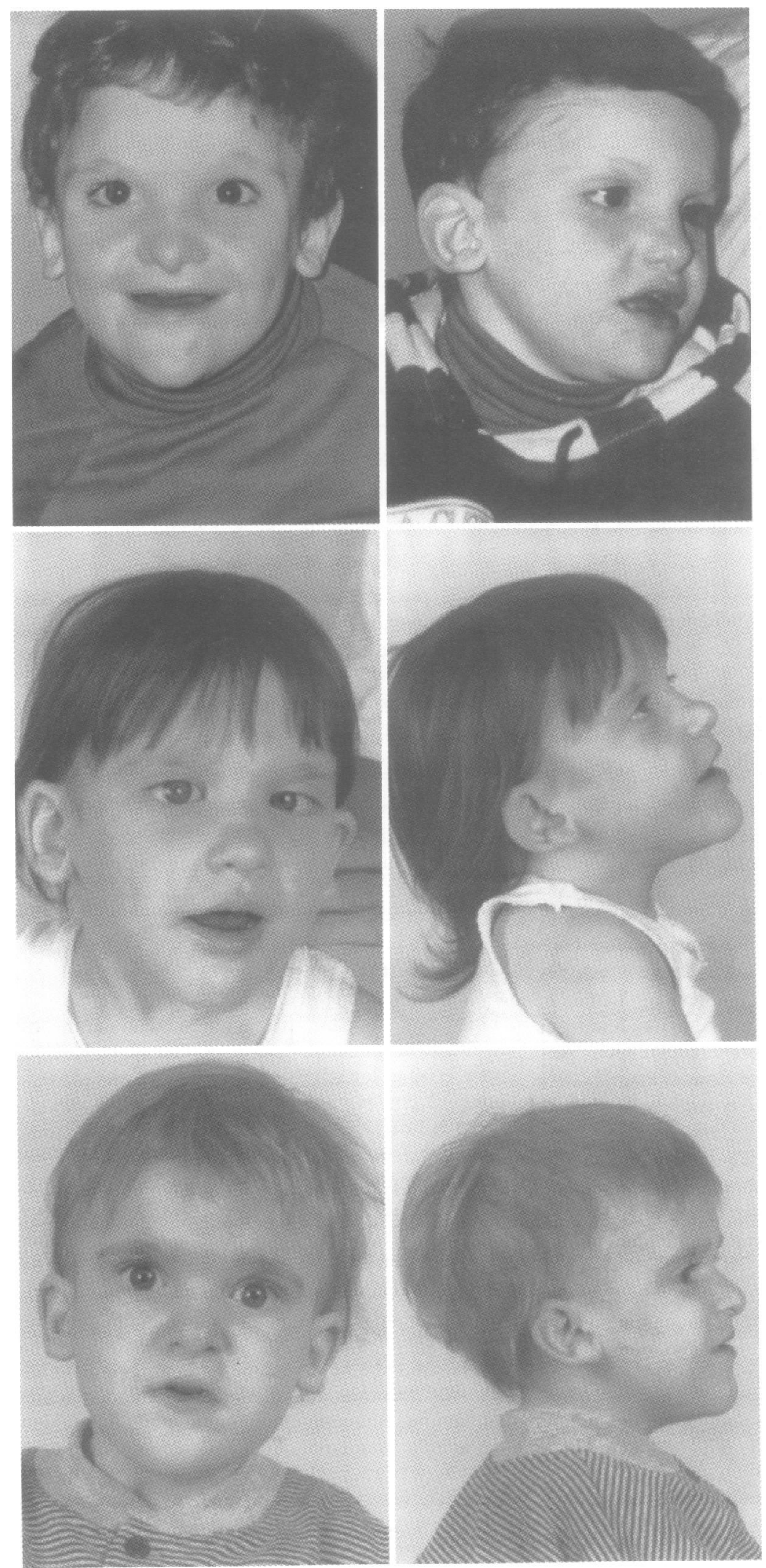

Figure 1 (Top row) Patient 1 at $41 / 2$ years of age. (Middle row) Patient 2 at 3 years of age. (Bottom row) Patient 3 at 3 years of age.

slanting palpebral fissures, broad nasal bridge, bulbous nasal tip, prominent columella, triangular jaw, prognathism, open mouthed facial expression, low set, posteriorly rotated ears with uplifted lobes, tapered fingers, and bilateral single transverse palmar creases. Neurological examination showed reduced lower limb tone and generalised hyperreflexia. Investigations including skeletal survey, urinary amino and organic acids, and karyotype at 550 band resolution were normal.

PATIENT 2 (FIG 1)

This girl is the third of four children of non-consanguineous parents; her birth weight was $4820 \mathrm{~g}$, length $52 \mathrm{~cm}$, and head circumference $34 \mathrm{~cm}$. Short segment HSCR was diagnosed at 6 weeks of age after she presented with vomiting and failure to thrive. Right upper transverse colostomy was performed at the age of 7 weeks, followed by Duhamel rectosigmoidectomy at the age of 8 months. She had hypotonia and global developmental delay. She started to crawl, sat unsupported, and started to babble at 2 years of age. Seizures started at 18 months and initially responded to anticonvulsants, but she has gradually developed a resistant seizure disorder with episodes of status epilepticus. She wears glasses for hypermetropia and her hearing is normal. At 3 years of age she was able to stand and cruise, had no speech, but smiled frequently and had a happy, affectionate personality.

On examination her height was $89 \mathrm{~cm}(<3 \mathrm{rd}$ centile), weight $12 \mathrm{~kg}(<3 \mathrm{rd}$ centile), and head circumference $44.5 \mathrm{~cm}$ ( $<3 \mathrm{rd}$ centile). She had fine, somewhat sparse hair, deep set blue eyes, left ptosis, convergent strabismus, uplifted earlobes, bulbous nasal tip, prominent columella, long face, triangular chin, prognathism, open mouthed expression, high arched palate, long, tapered fingers, fetal finger tip pads, bilateral fifth finger clinodactyly, and bilateral pes planus with calcaneovalgus. Cranial ultrasound at 4 months of age suggested partial agenesis of the corpus callosum, but later cranial CT and MRI were normal. Renal ultrasound and micturating cystourethrogram were normal. G banded karyotype was normal at 650 band resolution.

PATIENT 3 (FIG 1)

This boy is the second child of nonconsanguineous parents. His birth weight was $3400 \mathrm{~g}$, length $49.5 \mathrm{~cm}$, and head circumference $33.5 \mathrm{~cm}$. At the age of 6 weeks he developed respiratory distress and was found to have complex cyanotic heart disease consisting of pulmonary atresia, ventricular septal defect, and dysplastic mitral valve. He was a very irritable infant with difficult feeding and failure to thrive. $\mathrm{He}$ had a Nissen fundoplication at 2 years, but poor growth and irritability continued. At 3 years of age, as a result of continued feeding difficulties, colicky abdominal pain, and constipation, he underwent rectal biopsy; short segment Hirschsprung disease was diagnosed and a transverse colostomy was performed. He experienced one generalised seizure at the age of 17 months. He underwent cardiac bypass surgery at the age of 4 years and developed recurrent seizures postoperatively; these have since come under reasonable control with sodium valproate and lamotrigine. At the age of $4 \frac{1}{2}$ years he could sit independently, walked in a walker, and had several recognisable words.

On examination at the age of $31 / 2$ years, his length was $88 \mathrm{~cm}$ ( $<3 \mathrm{rd}$ centile), weight $11 \mathrm{~kg}$ 

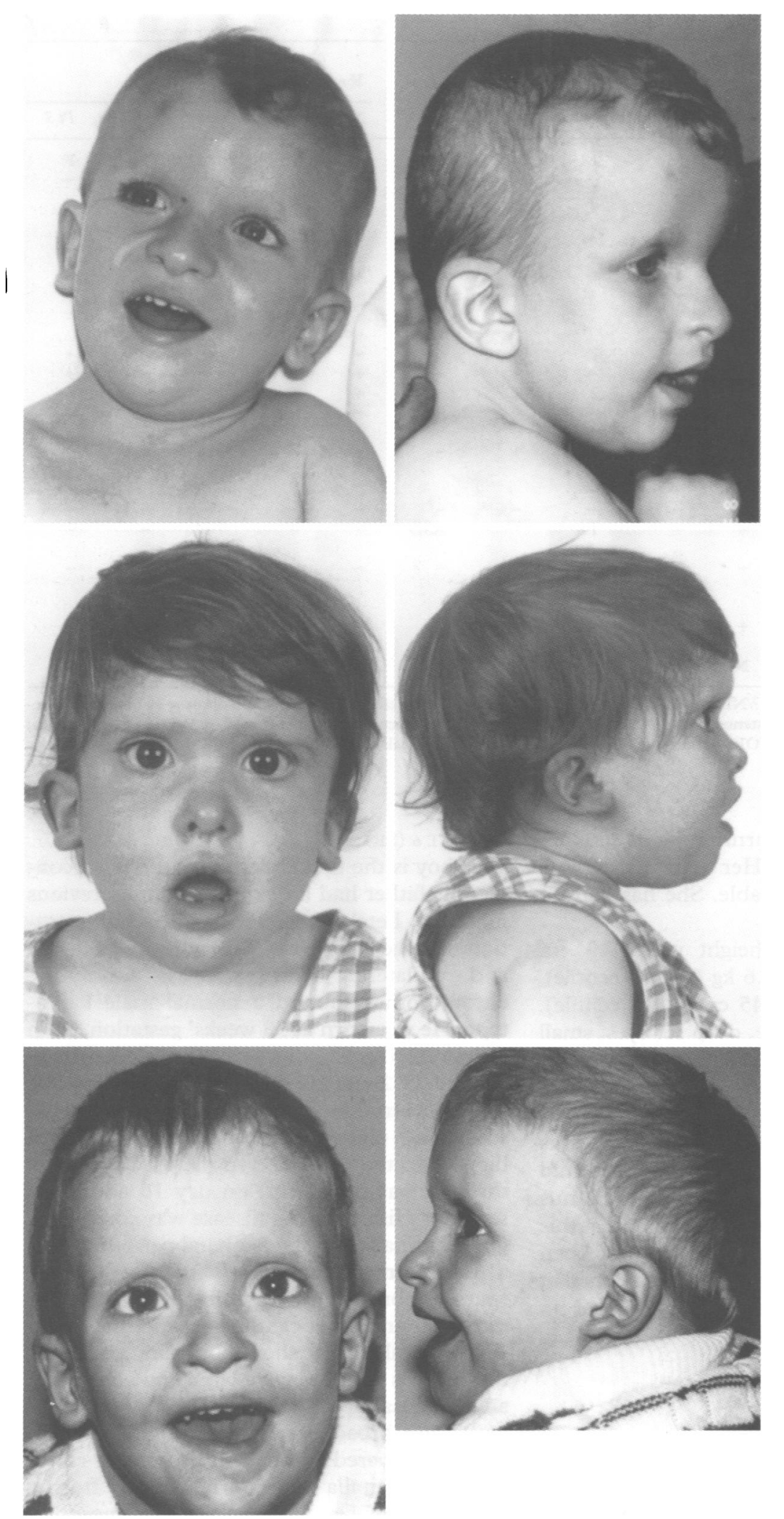

Figure 2 (Top row) Patient 4 at 21/2 years of age. (Middle row) Patient 5 at 2 years 10 months of age. (Bottom row) Patient 6 at 2 years 6 months of age.

( 3 rd centile), and head circumference $46.5 \mathrm{~cm}$ ( $<3$ rd centile). He had a long face, deep set blue eyes, wide nasal bridge, bulbous nasal tip, small, posteriorly rotated ears with prominent anteverted lobes, small mouth often held open, short palate with a small submucous cleft, hypoplastic nipples, undescended testes, shawl scrotum, tapered fingers, and bilateral pes planus with calcaneovalgus. Cranial CT scan, G banded karyotype at 450 band resolution, and chromosome 22q11 FISH were normal.

PATIENT 4 (FIG 2)

This boy was the first child of unrelated parents who had had one previous miscarriage. Prenatal ultrasound at 18 weeks' gestation showed bilateral dilated renal calyces and at 28 weeks showed a duplex right kidney. He was born at 42 weeks' gestation by emergency LSCS for fetal distress; his birth weight was $3950 \mathrm{~g}$, length $55 \mathrm{~cm}$, and head circumference 35.5 $\mathrm{cm}$. He had a right preauricular tag, perineal hypospadias, bifid scrotum, and bilateral talipes calcaneovalgus. He developed abdominal distension on day 2 , rectal biopsy confirmed HSCR, and he underwent rectosigmoid colectomy and colostomy on day 9 . He had feeding difficulties in the first year of life and still only tolerates a pureed diet. He developed seizures at 2 years, which initially responded to anticonvulsants, but became resistant to treatment after the age of 3 years. He had intermittent patching of his right eye for a convergent strabismus; ophthalmological examination as a neonate suggested a coloboma of the right optic disc, but later was normal apart from prominent pigment rims around both optic discs. At 3 years of age, he was globally developmentally delayed with no speech, was not walking, but he was generally happy and smiling.

On examination his head circumference was $46.5 \mathrm{~cm}$ ( 3 rd centile), height $92 \mathrm{~cm}$ (50th centile), and weight $12 \mathrm{~kg}$ ( $<3 \mathrm{rd}$ centile). He had sparse, fine hair with a frontal cowlick, prominent metopic suture, large but deep set blue-grey eyes, rounded nasal tip, long columella, open mouth, large bifid upper left central incisor, prominent, triangular chin, low set ears with uplifted ear lobes, mild pectus excavatum, and left single transverse palmar crease. Renal ultrasound showed a duplex right kidney and cranial ultrasound at 2 weeks of age suggested partial agenesis of the corpus callosum; MRI at 4 years showed complete agenesis of the corpus callosum. $\mathrm{G}$ banded karyotype at 550 band resolution (fig 3) showed $\operatorname{del}(2)$ (q21 q23).

PATIENT 5 (FIG 2)

This girl was referred to the genetics unit by her paediatrician, who also cares for patient 3, because she had a similar facial phenotype, although she did not have known HSCR. She is the sixth child of unrelated parents; her birth weight was $3500 \mathrm{~g}$, length $49 \mathrm{~cm}$, and head circumference $34 \mathrm{~cm}$. She had early feeding difficulties, gastro-oesophageal reflux, hypotonia, and failure to thrive. At 9 months a cardiac murmur was detected and echocardiogram showed tetralogy of Fallot and atrial septal defect, which were surgically repaired at 11 months. She has had constipation from about the age of 12 months, adequately controlled by regular prune and apple juice, but had one episode of abdominal discomfort and distension at 22 months, during which plain abdominal imaging showed marked gaseous dilatation of the small and large bowel. At 2 years 10 months she was vocalising but had no recognisable 
Table 1 Summary of reported patients with HSCR, MR, and microcephaly

\begin{tabular}{|c|c|c|c|c|c|c|c|c|c|c|c|}
\hline \multirow[b]{2}{*}{ Clinical manifestations } & \multicolumn{2}{|c|}{$\begin{array}{l}\text { Goldberg and } \\
\text { Shprintzen }\end{array}$} & \multirow{2}{*}{$\begin{array}{l}\text { Brunoni } \\
\text { et } a l^{3}\end{array}$} & \multicolumn{2}{|c|}{$\begin{array}{l}\text { Kumasaka and } \\
\text { Clarren }^{2}\end{array}$} & \multirow{2}{*}{$\begin{array}{l}\text { Halal } \\
\text { - and } \\
\text { Morel }^{5}\end{array}$} & \multicolumn{2}{|c|}{ Yomo et al } & \multicolumn{3}{|c|}{ Hurst et al $l^{4}$} \\
\hline & Sib 1 & Sib 2 & & Sib 1 & Sib 2 & & Sib 1 & Sib 2 & $\operatorname{Pt} 1$ & Pt 2 & Pt 3 \\
\hline Sex $\ldots$ & $\mathbf{M}$ & $\mathrm{F}$ & $\mathbf{M}$ & $\mathbf{M}$ & $\mathbf{M}$ & $\mathbf{M}$ & $\mathbf{M}$ & $\mathrm{F}$ & $\mathbf{M}$ & $M$ & $\mathbf{F}$ \\
\hline Consanguinity & - & - & - & - & - & - & - & - & + & + & - \\
\hline \multicolumn{12}{|l|}{ Core features } \\
\hline Mental retardation & + & + & + & + & + & + & + & + & + & + & + \\
\hline Microcephaly & + & + & + & + & + & + & + & + & + & + & + \\
\hline HSCR & + & + & + & + & - & + & + & + & + & + & + \\
\hline Short stature & + & + & - & + & + & + & + & + & - & + & + \\
\hline \multicolumn{12}{|l|}{ Facial features } \\
\hline Typical & - & - & - & $?$ & $?$ & - & - & - & - & - & + \\
\hline Sparse hair & + & + & - & - & - & - & + & + & - & - & + \\
\hline Eyebrow abn & + & + & + & $?$ & $?$ & - & + & + & - & - & + \\
\hline Coloboma & - & - & - & - & - & - & - & - & + & - & + \\
\hline Ptosis & - & - & - & - & - & - & + & + & - & - & + \\
\hline Cleft palate/lip & Sub & Sub & + & Sub & + & - & - & - & - & - & - \\
\hline \multicolumn{12}{|l|}{ Other features } \\
\hline Seizures & - & - & - & - & - & - & - & - & - & - & - \\
\hline Congenital heart disease & - & - & - & PS & - & ASD & - & - & - & - & - \\
\hline Renal & - & - & - & $?$ & $?$ & - & - & - & - & VUR & - \\
\hline \multicolumn{12}{|l|}{ Investigations } \\
\hline Abn cranial CT/MRI/US & + & + & $?$ & $?$ & $?$ & + & + & + & + & + & - \\
\hline Chromosomes & $\mathbf{N}$ & ND & $\mathbf{N}$ & ? & $?$ & $\mathbf{N}$ & $\mathrm{N}$ & $\mathbf{N}$ & $\mathbf{N}$ & ND & $\mathbf{N}$ \\
\hline
\end{tabular}

+=present; -=absent; $\mathrm{N}=$ normal; ? $/ \mathrm{ND}=$ =unknown/not done; $\mathrm{ASD}=$ atrial septal defect; Hydro=hydronephrosis; PDA=patent ductus arteriosus; PS=pulmonary stenosis; Dup=duplex kidney; COARC=coarctation of the aorta; PA=pulmonary atresia; $\mathrm{ACC}=$ agenesis corpus callosum; $\mathrm{TOF}=$ tetralogy of Fallot; Sub=submucous cleft palate; ${ }^{\star}=$ constipation; PPS=peripheral pulmonary stenosis.

words, cruised around furniture, and took an occasional single step. Her personality was generally happy and sociable. She has had no seizures.

On examination her height was $77.9 \mathrm{~cm}$ ( $<<3$ rd centile), weight $9.6 \mathrm{~kg}$ ( $<<3$ rd centile), and head circumference $45 \mathrm{~cm}$ ( $<3 \mathrm{rd}$ centile). She had a long face, large, deep set eyes, small nose with a bulbous tip, prominent columella, open mouthed expression, tented upper lip, pointed chin, high arched palate with small, broad uvula, uplifted ear lobes, mild pectus excavatum, slender, tapered fingers, mild bilateral metatarsus adductus and pes planus with calcaneovalgus. Cranial ultrasound at this age was normal. Renal imaging has not been performed. $G$ banded karyotype was normal at 650 band resolution. Rectal biopsy showed no evidence of aganglionosis.

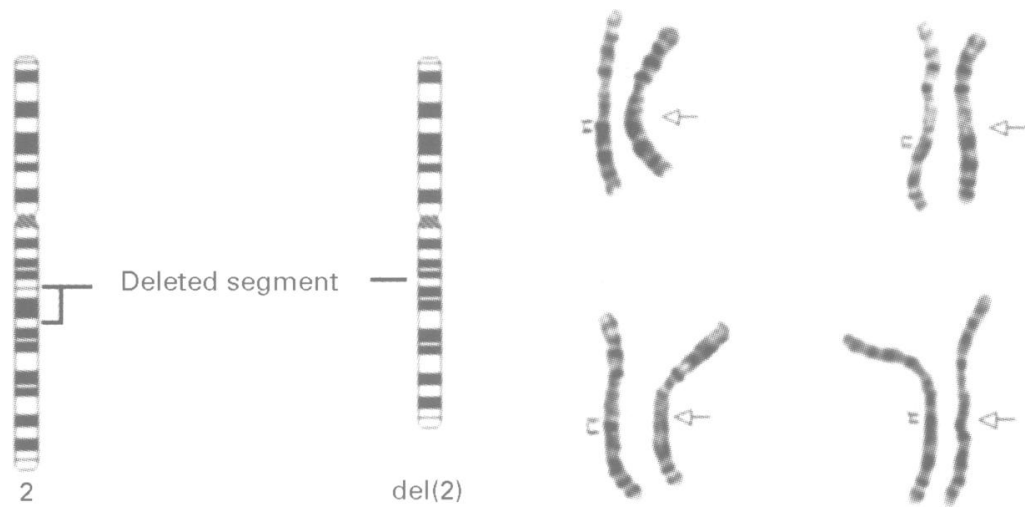

Figure 3 Ideogram and four partial karyotypes showing the normal and deleted chromosomes 2; del(2) (q21q23) on the right. The segment involved in the deletion is framed on the normal chromosome 2 and the breakpoint is indicated by the arrow on the deleted chromosome 2.
PATIENT 6 (FIG 2)

This boy is the first child of an unrelated couple; his father had a daughter from a previous marriage. Fetal ultrasound at 24 weeks' gestation showed agenesis of the corpus callosum and unilateral hydronephrosis. Amniocyte chromosomes showed a normal male karyotype. He was born at 38 weeks' gestation, birth weight $2210 \mathrm{~g}$, length $43 \mathrm{~cm}$, and head circumference $29.2 \mathrm{~cm}$. He developed symptoms of a bowel obstruction and the diagnosis of Hirschsprung disease was confirmed on rectal biopsy at the age of 3 days. A Soave pull through was performed on day 10 and short segment Hirschsprung disease was confirmed. On examination in the neonatal period, he had a high, broad forehead with turricephaly, sparse eyebrows with no visible eyelashes, normal inner and outer canthal measurements, flat supraorbital ridges, short philtrum, and small mouth. His earlobes were large and anteverted and his nasal tip broad with a prominent columella and broad nasal alae. His fingers were long and tapered and he had prominent calcanei. His genitalia were normal, apart from a hooded prepuce. Lymphocyte chromosomes confirmed a normal male karyotype. Echocardiograph showed a small patent ductus arteriosus, and renal ultrasound showed persistent dilatation of the right pelvicalyceal system and ureter but micturating cystourethrogram was normal. Formal ophthalmological assessment, skeletal survey, urinary amino and organic acids, plasma long chain fatty acids, and 7-dehydrocholesterol were normal.

On review at 13 months of age, there was severe developmental delay. He could roll and was able to sit with support; babbling and 
Table 1 continued

\begin{tabular}{|c|c|c|c|c|c|c|c|}
\hline \multirow[b]{2}{*}{ Tanaka et al } & \multirow[b]{2}{*}{ Lurie et al ${ }^{7}$} & \multicolumn{6}{|c|}{ Our patients } \\
\hline & & Pt 1 & Pt 2 & $\operatorname{Pt} 3$ & $\operatorname{Pr} 4$ & $\operatorname{Pt} 5$ & Pt 6 \\
\hline F & $\mathbf{M}$ & $\mathbf{M}$ & $\mathbf{F}$ & $\mathbf{M}$ & $\mathbf{M}$ & $\mathbf{F}$ & $\mathbf{M}$ \\
\hline- & - & - & - & - & - & - & - \\
\hline+ & + & + & + & + & + & + & + \\
\hline+ & + & + & + & + & + & + & + \\
\hline+ & + & + & + & + & + & $-\star$ & + \\
\hline+ & + & + & + & + & - & + & + \\
\hline+ & + & + & + & + & + & + & + \\
\hline$?$ & $?$ & - & + & + & + & - & + \\
\hline+ & $?$ & + & + & + & + & - & + \\
\hline- & - & - & - & - & - & - & - \\
\hline- & - & - & + & $\bar{s}_{\mathrm{s}}$ & - & - & - \\
\hline - & - & - & - & Sub & - & - & - \\
\hline+ & + & + & + & + & + & - & - \\
\hline PDA/ASD & $\begin{array}{l}\text { PDA/ASD } \\
\text { COARC }\end{array}$ & - & - & PA & - & TOF & $\begin{array}{l}\text { PDA/ } \\
\text { PPS }\end{array}$ \\
\hline- & - & VUR & - & - & Dup & - & Hydro \\
\hline+ & $?$ & N CT & N MRI & N CT & ACC MRI & N US & $\begin{array}{l}\text { ACC } \\
\text { MRI }\end{array}$ \\
\hline $\mathbf{N}$ & del 2 q22-q23 & $\mathbf{N}$ & $\mathrm{N}$ & $\mathbf{N}$ & $\begin{array}{l}\text { del } \\
2 \mathrm{q} 21-\mathrm{q} 23\end{array}$ & $\mathbf{N}$ & $\mathbf{N}$ \\
\hline
\end{tabular}

laughing were reported. He could drink from a bottle and took pureed foods. Absent visual responses had been noted by 4-5 months of age with only transient fixing and following, despite structurally normal eyes. Audiological assessment had shown partial responses at both high and low frequencies, excluding a major degree of hearing loss. He had always been a happy, contented baby. His head circumference was $44 \mathrm{~cm}$ (3rd centile) and weight $8 \mathrm{~kg}$ (3rd-10th centile). The clinical features seen in the neonatal period were confirmed. He had sparse hair, laterally sparse eyebrows, deep set eyes, and an open mouthed expression. There was marked generalised hypertonia and hyperreflexia with crossed adductor responses. Cerebral MRI at 15 months confirmed absence of the corpus callosum, with moderate dilatation of the posterior and temporal horns of the lateral ventricles. The myelination pattern was delayed, and there was some periventricular high signal seen around the occipital lobes, possibly representing dysmyelination. Echocardiography at the same age confirmed the persistence of a tiny patent ductus arteriosus with a mild branch pulmonary stenosis. He was recognised to have the same syndrome as the previous patients following discussion and comparison of clinical photographs by two of the authors.

Molecular investigations and results Ten highly polymorphic microsatellite markers (D2S2215, D2S114, D2S127, D2S122, D2S151, D2S2301, D2S356, D2S2241, D2S2299, D2S2370), listed in assumed order from centromere to telomere, spanning a distance of $23 \mathrm{cM}^{16}$ on chromosome $2 \mathrm{q}$, were typed for patients 1 to 5 and their parents. A further two markers (D2S333 and D2S326),
11 and $13 \mathrm{cM}$ respectively towards the telomere from D2S2370, were also typed. Markers D2S114, D2S127, and D2S122 showed loss of heterozygosity $(\mathrm{LOH})$ in patient 4 , consistent with the observed cytogenetic deletion. The telomeric boundary for this deletion was established as between markers D2S122 and D2S151, and the centromeric boundary between D2S114 and D2S2215. Patient 2 was uninformative for the markers D2S114, D2S127, and D2S122 and therefore loss of heterozygosity could not be ruled out at these loci. Patients 1, 3, and 5 showed no evidence of $\mathrm{LOH}$ at these markers.

\section{Discussion}

The children we report here share strikingly similar facial features, including deep set, large eyes (blue in four patients), broad nasal bridge, rounded nasal tip, prominent columella, open mouthed expression, triangular jaw, prominent chin, and large uplifted ear lobes, in association with $M R$ and microcephaly. Five have proven HSCR (four with short segment) and one has chronic constipation but a normal rectal biopsy. They share musculoskeletal features, including postnatal short stature, slender, tapered fingers, and bilateral calcaneovalgus. Three of our patients have congenital heart disease and three have renal structural abnormalities. All have severe developmental delay with absent or minimal speech and delayed gross motor skills, but a generally happy, smiling affect, and four have developed epilepsy, which has become resistant to treatment in two. In four patients, cerebral ultrasound in early infancy suggested complete or partial agenesis of the corpus callosum (ACC); later cerebral CT was normal in two with suggested partial ACC on ultrasound, while MRI confirmed complete ACC in the other two patients. One patient had a normal cerebral ultrasound and one a normal cerebral CT in infancy.

Table 1 lists the features of our patients and compares these with the 13 previously reported children with the association of HSCR, MR, microcephaly, and dysmorphic facial features. On review of these reports, we considered that three other patients definitely had the same facial phenotype. ${ }^{4 \text { (case } 3) 6} 8$ All of these were isolated cases. The patient reported by Lurie $e t$ $a l^{\beta}$ had a deletion of $2 \mathrm{q} 22-\mathrm{q} 23$ and our patient 4 had a deletion of 2q21-q23 (fig 3). Lurie et al compared the phenotypic features of eight patients with interstitial deletions including 2q22-23, and concluded the observed spectrum of anomalies did not allow the delineation of a consistent clinical syndrome. Six patients had congenital heart disease, four had cleft palate, and two had ocular colobomata. Only one had diagnosed HSCR, and the published photograph showed a strong facial resemblance to our patients. Of the remainder, none of the available photographs in the original references $^{9101213}$ enabled us to identify a similar facial phenotype, and some were only reported as neonates, so the subsequent clinical course, particularly with regard to milder forms of HSCR, was not known. Three of these 
patients had more extensive deletions incorporating 2q22-23, and two more had deletion breakpoints at either $2 \mathrm{q} 22$ or $2 \mathrm{q} 23$. It is possible that the clinical differences, particularly in those with deletions also involving 2q24, could be caused by an overriding phenotype. Five of the six patients we report did not have cytogenetically detectable deletions, at 450 to 650 band resolution, nor could we confirm the presence of a molecular deletion in any of these patients with the markers tested. So far, we have not been able to delineate the critical region for the observed phenotype, which could be caused by a contiguous gene syndrome, or a single gene disorder, or disruption of a critical region within 2q22-23. It is also possible that there is genetic heterogeneity and that other genetic loci could give rise to the same phenotype.

A number of genes for HSCR have been identified including the RET proto-oncogene (10q11.2), ${ }^{17} 18$ EDNRB (13q22), ${ }^{19} 20$ EDN3 (20q13.2-q13.3) ${ }^{21} 22$ and the RET ligand, and glial cell line derived neurotropic factor (GDNF) (5p13.1). ${ }^{23}{ }^{24}$ No previous loci have been identified on chromosome 2q. Mutational analysis has shown that HSCR can be associated with different genetic mechanisms including autosomal dominant and recessive inheritance. ${ }^{17-24}$ In familial HSCR caused by a postulated loss of function mutation in the RET proto-oncogene, variable intrafamilial expressivity (short segment and long segment disease) and non-penetrance (29\% in males and $50 \%$ in females) have been described..$^{25}$ A similar mechanism, possibly secondary to other HSCR gene polymorphisms,${ }^{24}$ could be operating to explain both the variable expressivity and penetrance of HSCR in our patients and the apparent low frequency of HSCR in the previously reported patients with deletions incorporating 2q22-23.

We could not confirm the facial phenotype exhibited by our patients on review of published photographs of the two sibs reported by Goldberg and Shprintzen ${ }^{1}$ and eight other patients subsequently reported as possible Goldberg-Shprintzen syndrome. ${ }^{257}$ Eight of these 10 cases involved sib recurrence or parental consanguinity. There were a number of congenital anomalies shared with some of our patients, including congenital heart disease, submucous cleft palate, and structural cerebral abnormalities, in particular complete or partial agenesis of the corpus callosum. These anomalies are frequently documented in numerous other syndromes involving HSCR, which may not have either MR or microcephaly, so are likely to result from disruption of normal neural crest cell migration by a variety of different mechanisms. This suggests that there is genetic heterogeneity within the group of patients presenting with HSCR, MR, and microcephaly, some of whom, including our patients, could have a contiguous gene syndrome or new dominant mutation, while others, such as those reported by Goldberg and Shprintzen, ${ }^{1}$ could have separate autosomal recessive disorders.
Following the recognition of a similar phenotype in our first two cases, the next three were identified within the next six months, and we suspect this could be a relatively common syndrome in children with syndromic HSCR. Recognition of the syndrome has important implications in regard to clinical management and genetic counselling. Affected patients may have chronic abdominal discomfort or constipation secondary to unrecognised short segment HSCR. These symptoms are common in hypotonic, delayed children, but identification of the characteristic facies in a child with microcephaly and developmental delay, in association with chronic abdominal symptoms, should prompt consideration of rectal biopsy, high resolution analysis of chromosome $2 \mathrm{q}$, and molecular studies with probes localised to 2q22-23. Genetic counselling would also be aided by recognition of this disorder. All of our patients, and those previously published patients whom we consider have the same syndrome, have been isolated cases, some from large sibships, and two have de novo deletions involving chromosome $2 \mathrm{q}$. This suggests a low recurrence risk should apply to most families, although at present sib recurrence secondary to parental germline mosaicism cannot be excluded. This is in comparison to the $25 \%$ recurrence risk which applies to families with autosomal recessive syndromes of HSCR, MR, and microcephaly.

We should like to thank the families of these children for their cooperation.

1 Goldberg RB, Shprintzen RJ. Hirschsprung megacolon and cleft palate in two sibs. $\not$ Craniofac Genet Dev Biol cleft palate

2 Kumasaka K, Clarren SK. Familial patterns of central nervous system dysfunction, growth deficiency, facial clefts and congenital megacolon: a specific disorder? $A m \mathcal{F}$ Med Genet 1988;31:465-6.

3 Brunoni D, Joffe R, Farah LMS, et al. Hirschsprung megacolon, cleft lip and palate, mental retardation, and minor congenital malformations. $\mathcal{F}$ Clin Dysmorphol 1983;1:20-2

4 Hurst JA, Markiewicz M, Kumar D, et al. Unknown syndrome. Hirschsprung's disease, microcephaly, and iris coloboma: a new syndrome of defective neuronal migration. $\mathcal{F}$ Med Genet 1988;25:494-500

5 Halal F, Morel J. The syndrome of Hirschsprung disease, microcephaly, unusual face, and mental retardation. $A m \mathcal{F}$ Med Genet 1990;37:106-8.

6 Tanaka H, Ito J, Cho K, Mikawa M. Hirschsprung disease, unusual face, mental retardation, epilepsy, and congenital unusual face, mental retardation, epilepsy, and congenital heurol 1993;9:479-81.

7 Yomo A, Taira T, Kondo I. Goldberg-Shprintzen syndrome: Hirschsprung disease, hypotonia, and ptosis in sibs. $A m \mathcal{f}$ Med Genet 1991;41:188-91.

8 Lurie IW, Supovitz KR, Rosenblum-Vos LS, Wulfsberg EA Phenotypic variability of $\operatorname{del}(2)$ (q22-q23): report of a case and review of the literature. Genet Counsel 1994;5:11-14.

Fryns JP, Van Bosstraeten B, Malbrain H, Van den Berghe $\mathrm{H}$. Interstitial deletion of the long arm of chromosome 2 in a polymalformed newborn - karyotype: $46, \mathrm{XX}, \operatorname{del}(2)(\mathrm{q} 21$ q24). Hum Genet 1977;39:233-8.

10 McConnell TS, Kornfield M, McClellan G, Aase J. Partial deletion of chromosome 2 mimicking a phenotype of trisomy 18: case report with autopsy. Hum Pathol 1980;11:202-5.

11 Palmer CG, Heerema N, Bull M. Deletions in chromosome 2 and fragile sites. Am $\mathcal{F}$ Med Genet 1990;36:214-18.

12 Shabtai F, Klar D, Halbrecht I. Partial monosomy of chromosome 2. Delineable syndrome of deletion 2 chromosome 2. Delineable syndrom

13 Takahashi Y, Narahara K, Kikkaw K, et al. Interstitial deletion of the long arm of chromosome $2:$ a case report and
review of the literature. fpn f Hum Genet 1985;30:297305.

14 Valera-Huezo S, Fragoso R, Rivera H, et al. $\operatorname{Del}(2)$ (q23.00 q24.10) de novo. Bol Med Hosp Infant 1986;43:375-7.

15 Woods CG, Koehn DC, McFadden DE, et al. A case repor of a child with an interstitial deletion of chromosome 2 (q22-q24.2) and the VATER association phenotype Abstracts of the DW Smith Workshop on Malformations and Morphogenesis. Salem: Winston, 1992:59. 
16 Dib C, Faure S, Fizames C, et al. A comprehensive map of the human genome based on 5,264 microsatellites. Nature 1996; 380:152-4

17 Edery P, Lyonnet S, Mulligan LM, et al. Mutations of the RET proto-oncogene in Hirschsprung's disease. Nature 1994;367:378-80.

18 Romeo G, Ronchetto P, Luo Y, et al. Point mutations affecting the tyrosine kinase domain of the RET proto-oncogene in Hirschsprung's disease. Nature 1994;367:377-8.

19 Puffenberger EG, Hosoda K, Washington SS, et al. A mis-sense mutation of the endothelin-B receptor gene mis-sense mutation of the endothelin-B receptor gene
in multigenic Hirschsprung's disease. Cell 1994;79:1257-66.

20 Attie T, Till M, Pelet A, et al. Mutation of the endothelin-receptor B gene in the Waardenburgendothelin-receptor B gene in the Waardenb
Hirschsprung disease. Hum Mol Genet 1995;4:2407-9.

21 Edery P, Attie T, Amiel J, et al. Mutation of the endothelin-3 gene in the Waardenburg-Hirschsprung disease (ShahWaardenburg syndrome). Nat Genet 1996;12:442-4.
22 Hofstra RMW, Osinga G, Tan-Sindhunata G, et al. A homozygous mutation in the endothelin-3 gene associated with a combined Waardenburg type 2 and Hirschsprung phenotype (Shah-Waardenburg syndrome). Nat Genet 1996;12:445-7.

23 Saloman R, Attie T, Pelet A, et al. Germline mutations of the RET ligand GDNF are not sufficient to cause Hirschsprung disease. Nat Genet 1996;14:345-7.

24 Angrist $M$, Bolk $S$, Halushka $M$, et al. Germline mutations in glial cell-derived neurotropic factor (GDNF) and RET in a Hirschsprung disease patient. Nat Genet 1996;14:341-3.

25 Attie T, Pelet A, Edery P, et al. Diversity of RET proto-oncogene mutations in familial and sporadic Hirschsprung disease. Hum Mol Genet 1995;4:1381-6.

26 Bolk S, Ahgrist M, Croaker D, Kruglak L, Chakravarti M. Segregation of a susceptibility gene in RET-linked Hirschsprung families. Am $\mathcal{F}$ Hum Genet 1996;59:A1221. 